\title{
First-Year Engineering Bicycle Dissection as an Introduction to Sustainable Design
}

\author{
T. E. Doyle \\ Assistant Professor, Electrical and Computer Engineering \\ McMaster University \\ B. W. Baetz \\ Professor, Civil Engineering \\ McMaster University \\ B. Lopes \\ Graduate, Civil Engineering \\ McMaster University
}

Abstract

Introductory design in a common first year engineering programme requires a balance between prescribed demonstration and open ended design. As a method of motivating and engaging students, McMaster's first year design and graphics course has had success running a product dissection project; referred to as the Cornerstone Project. The Cornerstone project's goal is to create a base for an engineer's design education and technical communications. While the course domain is traditionally considered mechanical in nature, the concepts apply across all engineering disciplines. With greater public concern about the environment and sustainability, the Cornerstone project will introduce these considerations in design. The summer offering of the Engineering Design and Graphics course will run a pilot course to examine the dissection, modelling, and sustainability of a commuter bicycle. This paper will describe the project, discuss its results, and present examples of student submissions.

\section{Introduction}

McMaster University's first year engineering class has an enrollment of 850 to 1000 students per year. It is a common first year with approximately half of the students taking the Engineering Design and Graphics course each term (September - December, January - April). In the summer term, the course is offered with a limited enrollment.

The Design and Graphics course has two primary objectives in engineering design: visualization and technical communication. Students develop graphical visualization skills through technical sketching and explore technical communication through two-dimensional and three-dimensional computer-aided design. At the conclusion of the course the student have learned the necessary skills to read engineering drawings, create engineering drawing, and how to design using the solid modeling methodology.

The Cornerstone project was first offered in the summer of 2007 to 41 students. The summer enrollment is largely composed of students that struggled with the course material during the regular session. With the high attri- 
tion rate in engineering programmes [2], there is a pressing need to motivate students through differentiated instruction and practical application. This group of students was the first test case to determine if a dissection/reverseengineering project would effectively meet this requirement. At the conclusion of the summer course, the project was very well received by the students. The best illustration of this enthusiasm was the response that "I actually felt like I was an engineer." Based on the success of the summer course, the project was embedded in the regular first year course and has since added a course competition between the terms.

In the summer of 2009, the author has adapted the Cornerstone to include a sustainability for a bicycle dissection. Rather than being assigned products, each team is assigned a function component of the bicycle. In addition, each group must propose, design, and model a modification or attachment for the purpose of sustainability. The course teaching assistants each model their own lab section's bicycle frame and at the end of the course each group's work is combined onto the bicycle frame.

\section{Dissection / Reverse-Engineering}

As engineering accreditation bodies require more outcome-based curriculum and increased design content there has been some shift towards what the student can do rather than what the student will know. The dissection method of teaching design has been applied to freshmen engineering courses [3, 4, 5, 6, 7] as an effective method of teaching design and introducing engineering practice.

\subsection{McMaster Engineering First Year}

The McMaster University engineering first year is a common curriculum providing the foundation for upper year courses, regardless of discipline. The design and graphics course is composed of weekly lecture, CAD laboratories, and freehand sketching tutorials. The three components run in parallel: lectures introduce new topics; labs develop CAD and solid modeling skills; and tutorials teach technical freehand sketching and visualization skills. While each was effective, students had some difficulty resolving the connection between each component. The dissection approach was introduced to tie lecture, laboratory, and tutorial into a cohesive target to enhance motivation and overall learning.

\subsection{McMaster Engineering Cornerstone}

The McMaster Engineering Cornerstone project uses the dissection/reverse engineering approach. Groups are restricted 3 members within the same lab section and the dissection product is assigned based on laboratory day. During the academic year there are ten lab sections, with two running per day. In the past academic year the ten products selected for the course were: toy airplane, solar fan, jerky gun, grease gun, winch, bilge pump, strap ratchet, clamp, miniature mouse, amber siren. Products were selected based on number of parts, safety, cost ( $\$ 15)$, and availability. Using off-the-shelf products made product equivalence a challenge; a scaling factor was incorporated into the evaluation to compensate for differences. However, in the summer pilot we are using similar bicycles for the dissection. The project is divided into two components: conceptual and applied. The conceptual component is a group submission, whereas the applied component has both group and individual elements of assessment. After the final submission of the report and CAD files the individual group members then complete peer- and self-evaluations.

\section{The Cornerstone Project}

The project is framed as the group being newly hired engineers and as a small team their first assignment is to evaluate a competitor's prod- 
uct. Based on preliminary data from a preproduction model, the group must first review how the competitor's device works. Once receiving the production model, the team's task is to benchmark the product and create a technical report with a complete set of engineering drawings. In addition, the teams propose, design, and model modifications for the goal of sustainability.

\subsection{Design Review}

With an inspection of the product the team must sketch several isometric pictorials and explain how the product works in a short report that technically explain the mechanical operation. Based upon their explanation, the group must also state the total number of parts they believe make up the product, propose a benchmark procedure(s), and propose modification to the design.

This component has two goals:

1. independent research, and

2. technical communication.

The project bicycles are selected to be inexpensive and commonly available, so that most students would have likely used that style or one similar in function. It is this familiarity with the product that offers the most poignant result; many of the students must admit that they do not know how it works.

For most students, this is their first design and graphics course. The project is introduced after they have developed the basic skills in technical freehand sketching and software part modeling. The technical report requires them to assess how they communicate the conceptual design effectively between members and for the final submission.

\subsection{Applied Component}

In the second part of the project the group must:

1. benchmark the product and record results,
2. disassembles the product,

3. measure and model each part using a solid modeling software application,

4. assemble the product in the software application,

5. re-assemble the physical product,

6. design and model a modification for the goal of sustainability,

7. benchmark the product and record results, and

8. write a technical report of how the product works with a complete set of engineering drawings.

As a group the members divide the parts evenly among themselves for modeling and then combine them together for the final assembly. A level of approximation is permitted according to the part complexity and mechanical function, for example, a part which is key to the mechanical function of the product would be permitted very little approximation. The assembly required the group to integrate their parts and to make modifications for minimal interference. The final report consists of a technical description of operation, benchmark results, bill of materials, a part characteristics table (surface area, volume, radii of gyration), and a complete set of engineering drawings using the CSA drawing conventions. The material and finish are not required components of the assignment and all parts are assigned a density of $1 \mathrm{~kg} / \mathrm{m} 3$.

The group is assigned a time for an oral examination on the project and related course components. From this examination a portion of the group work is assessed as well as an individual mark. 


\section{Results}

\subsection{The Final Product}

Figure 1 illustrate the quality of final submissions from the past academic year, along with the complexity of the products. In general, all submissions are of similar high caliber. The bicycle dissection pilot is currently ongoing and result are positive; however, the scaling to a full first year class will be a significant challenge.

\section{References}

[1] A.B. Smith, C.D. Jones, and E.F. Roberts, "Article Title", Journal, Publisher, Location, Date, pp. 1-10.

[2] P. J. Jarosz, I. J. Busch-Vishniac, "A Topical Analysis of Mechanical Engineering Curricula", Journal of Engineering Education, July, 2006, pp. 241-248.

[3] T. E. Doyle, “”, Proceedings of the American Society of Engineering Education Annual Conference, 2009.

[4] S. Sheppard, R. Jenison, "Examples of Freshmen Design Education, International Journal of Engineering Education, 13(4), 1997, pp. 248-261.

[5] S. Sheppard, "Mechanical Dissection: An Experience in How Things Work", Proceedings of the Engineering Education: Curriculum Innovation \& Integration, January, 1992, pp. 610.

[6] R. E. Barr, D. Juricic, T. J. Krueger, L. S. Wall, B. H. Wood, "The Freshman Engineering Design Graphics Course at the University of Texas at Austin", Journal for Geometry and Graphics, 2(2), 1998, pp. 169-179.

[7] A. Spence, T. E. Doyle, "Product Centric CAD Education", Proceedings of the ComputerAided Design and Applications 2008. 
Toy Airplane Fall Term 2008
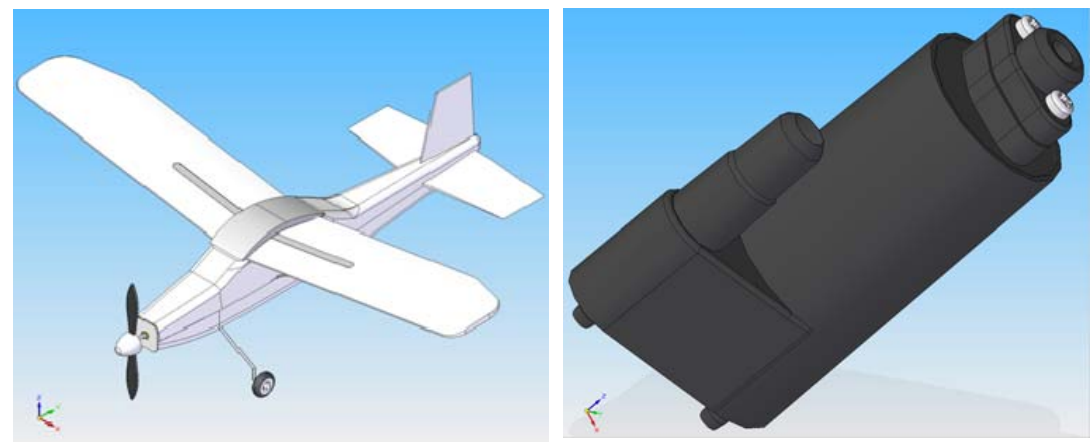

Solar Fan

Fall Term 2008
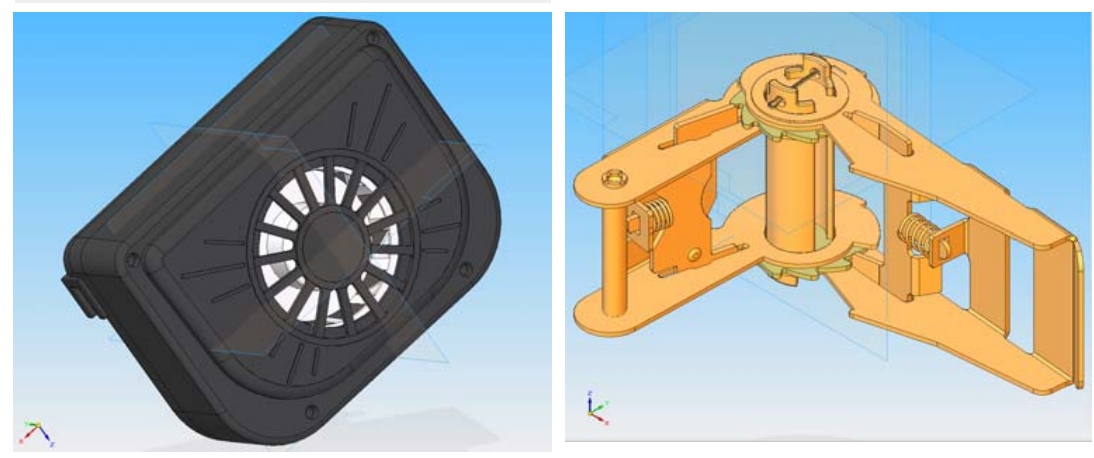

Jerky Gun

Fall Term 2008
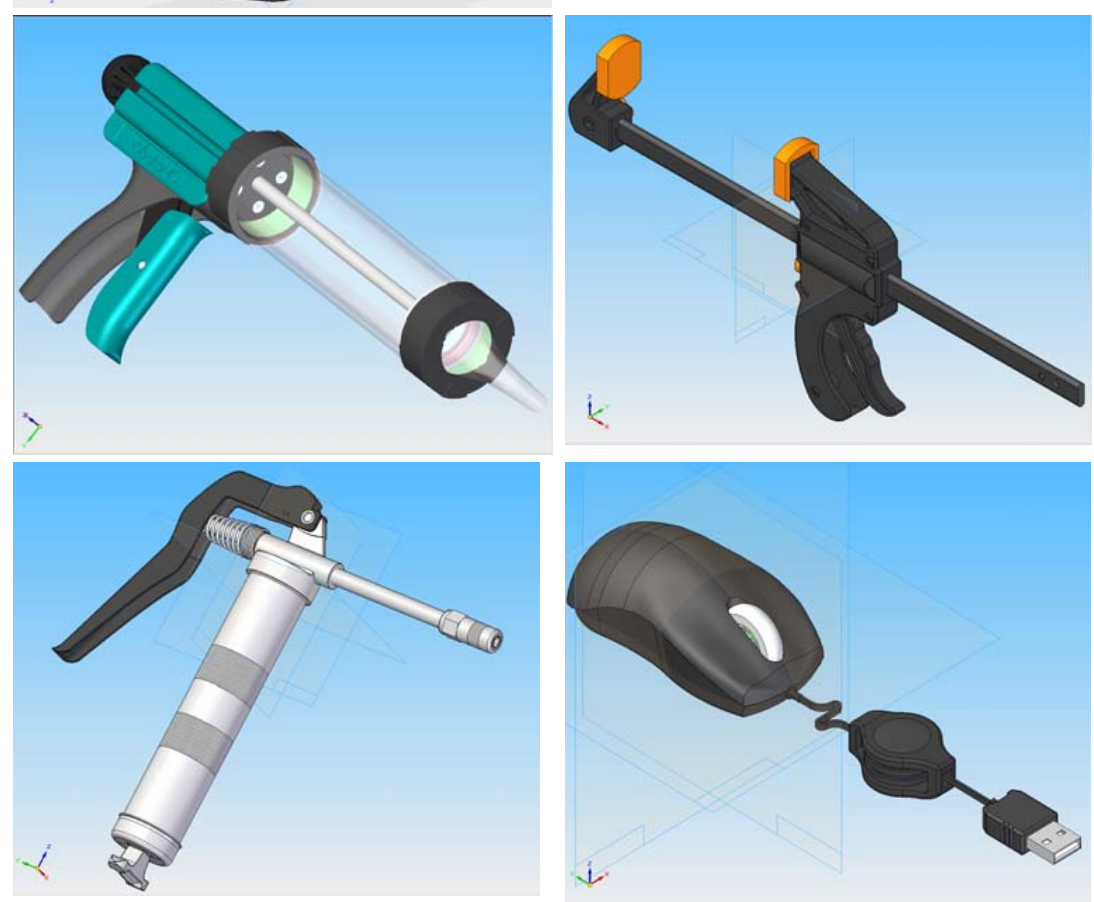

Grease Gun
Fall Term 2008

Winch

Fall Term 2008

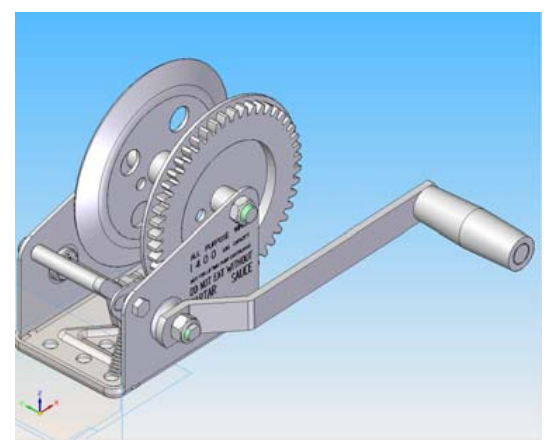

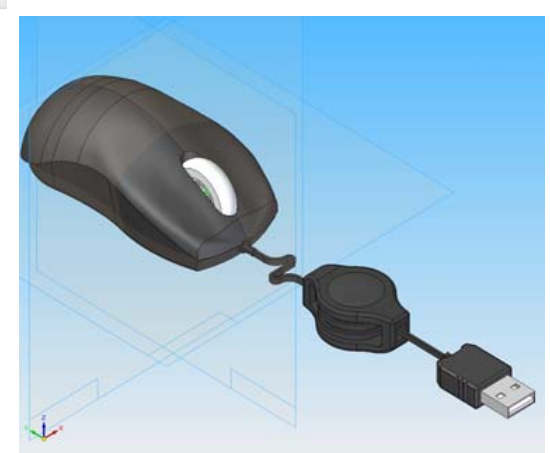

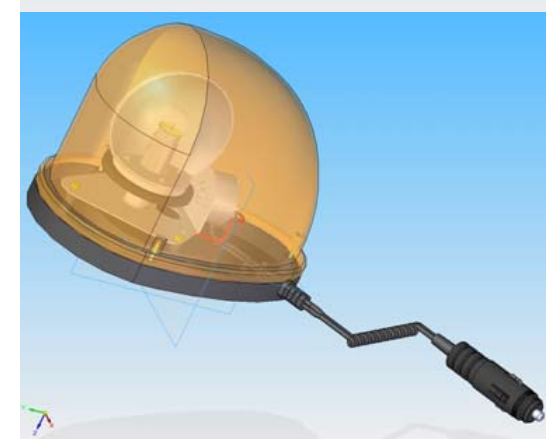

Bilge Pump

Winter Term 2008

Strap Ratchet

Winter Term 2008

Clamp
Winter Term 2008

Miniature Mouse

Winter Term 2008

Amber Lamp

Winter Term 2008

Figure 1: Summary of the Cornerstone Projects from Academic Year 2008. 